\title{
Structural and Magnetic Properties of Potassium-Doped 2,3-DiMethylnaphthalene
}

\author{
Xiao-Lin Wu ${ }^{1, * \mathbb{D}}$, Ren-Shu Wang ${ }^{2,3}$, Hui Yang ${ }^{4}$, Jie Zhang ${ }^{2}$, Ming-An Fu ${ }^{2}$, Shi-Chao Fang ${ }^{2}{ }^{\mathbb{D}}$, Xiao-Jia Chen ${ }^{3}$, \\ Yun Gao ${ }^{2}$ and Zhong-Bing Huang ${ }^{2, *}$
}

1 School of Physics and Electronic-Information Engineering, Hubei Engineering University, Xiaogan 432000, China

2 Faculty of Physics and Electronic Technology, Hubei University, Wuhan 430062, China; renshu.wang@hpstar.ac.cn (R.-S.W.); phzj@hubu.edu.cn (J.Z.); fumingan163@163.com (M.-A.F.); shichaofang@foxmail.com (S.-C.F.); gaoyun@hubu.edu.cn (Y.G.)

3 Center for High Pressure Science and Technology Advanced Research, Shanghai 201203, China; xjchen@hpstar.ac.cn

4 School of Physics and Mechanical \& Electrical Engineering, Hubei University of Education, Wuhan 430205, China; hyang@hue.edu.cn

* Correspondence: wuxiaolin937@163.com (X.-L.W.); huangzb@hubu.edu.cn (Z.-B.H.)

Citation: Wu, X.-L.; Wang, R.-S.; Yang, H.; Zhang, J.; Fu, M.-A.; Fang, S.-C.; Chen, X.-J.; Gao, Y.; Huang, Z.-B. Structural and Magnetic Properties of Potassium-Doped 2,3-DiMethylnaphthalene. Crystals 2021, 11, 608. https://doi.org/ $10.3390 /$ cryst 11060608

Academic Editor: Yulia Nelyubina

Received: 8 April 2021

Accepted: 25 May 2021

Published: 28 May 2021

Publisher's Note: MDPI stays neutral with regard to jurisdictional claims in published maps and institutional affiliations.

Copyright: (c) 2021 by the authors. Licensee MDPI, Basel, Switzerland. This article is an open access article distributed under the terms and conditions of the Creative Commons Attribution (CC BY) license (https:// creativecommons.org/licenses/by/ $4.0 /)$.

\begin{abstract}
The development of potential magnetic materials in metal-doped polycyclic aromatic hydrocarbons has been a research hotspot in recent years. Here we have successfully synthesized stable potassium-doped 2,3-dimethylnaphthalene samples. The combination of first-principles calculations and XRD results identifies that doping of potassium into 2,3-dimethylnaphthalene forms a monoclinic structure with a molar ratio of 1:2 between potassium and molecule. The red shifts in the Raman spectra indicate that potassium 4 s electrons are transferred to the organic molecules. The magnetic measurements show that the doped materials exhibit a temperature-independent magnetization in the temperature region of $1.8-300 \mathrm{~K}$, which is consistent with the Pauli paramagnetic behavior. This is distinct from the diamagnetism of pristine material. Compared to the previous focus on benzene ring structure, our study of aromatic hydrocarbon derivatives of benzene ring opens a new route for the development of this field.
\end{abstract}

Keywords: metal-doped; 2,3-dimethylnaphthalene; magnetism; first-principle calculation

\section{Introduction}

Charge injection into fullerene and graphitic compounds will lead to the emergence of unique properties in these carbon-based structures, including superconductivity [1-4], antiferromagnetism [5,6], and paramagnetism [7]. The delocalization of electrons on $\pi$ molecular orbitals is believed to play an important role in these materials. In the last decade, significant progress has been made in a variety of metal-doped polycyclic aromatic hydrocarbons (PAHs). For example, superconductivity in potassium doped picene [8], phenanthrene [9], phenacene [10], dibenzopentacene [11], coronene [12], p-oligophenyls [13-16], 2,2'-bipyridine [17], and triphenylbismuth [18-20] have been successfully exploited with the highest superconducting transition temperature $\left(T_{\mathrm{c}}\right)$ record of $123 \mathrm{~K}$, exceeding the $38 \mathrm{~K}$ of $\mathrm{Cs}_{3} \mathrm{C}_{60}$ [6]. Furthermore, some other properties have also been discovered in PAHs with metal insertion [21-26]. Potassium-doped 9-phenylanthracene $\left(\mathrm{K}_{3} \mathrm{C}_{20} \mathrm{H}_{14}\right)$ exhibited ferromagnetism in the low temperature zone [21]. Caesium-doped phenanthrene $\left(\mathrm{Cs}_{1} \mathrm{C}_{14} \mathrm{H}_{10}\right)$ is a Heisenberg antiferromagnet [22]. Crystalline $\mathrm{K}_{2}$ pentacene and $\mathrm{K}_{2}$ picene exhibited weak, temperature-dependent paramagnetic signals [25]. The diversity of magnetism enriches their application prospects in different situations.

In addition to the exploration of more magnetic PAHs, attention has been focused in recent years on the structural and electronic properties of PAHs in order to explain various magnetic properties discovered [27]. The antiferromagnetic coupling in phase-pure 
crystal of $[K(222)]_{2}\left[p\right.$-terphenyl $\left.l_{3}\right]$ that occurs in all three crystallographic directions was described by experimental results and density functional theory calculations [26]. The band structures of optimized $\mathrm{Na}_{3}$ triphenylene crystal showed that the insertion of sodium atoms causes the material to change into metal [28].

Potassium naphthate was used earlier for free-radical generation [29] and has shown antiferromagnetism [30]. It has also recently been reported that potassium doped naphthalene exhibits compensating ferromagnetism and semi-metallic properties using firstprinciples calculations [31]. Here, we investigate 2,3-dimethylnaphthalene (2,3-DMN) molecule in order to obtain stable potassium doped crystal structure through preparation process. We hope to modify the electronic structure and molecular interaction of naphthalene by means of methyl modification, so as to realize the modulation of its magnetic properties.

\section{Materials and Methods}

Potassium metal (purity 99\%) and pristine 2,3-DMN (purity $\geq 97 \%$ ) purchased from Sinopharm Chemical Reagent (Sinopharm Chemical Reagent Co.,Ltd., Shanghai, China) and Tokyo Chemical Industry (Tokyo Chemical Industry Co., Ltd., Tokyo, Japan) respectively were mixed adequately according to stoichiometric ratios of 1:1 or 2:1 in a wellconditioned glove box with $\mathrm{H}_{2} \mathrm{O}$ and $\mathrm{O}_{2}$ concentrations less than $0.1 \mathrm{ppm}$. The mixture was loaded into a special quartz tube and sealed to a high vacuum about $10^{-4} \mathrm{~Pa}$. The sealed tubes were placed in a high-power ultrasound device for $10 \mathrm{~h}$, and during this process the temperature of the tube was kept at $90{ }^{\circ} \mathrm{C}$. After ultrasound treatment, the sealed tubes were annealed at $130^{\circ} \mathrm{C}$ for 3 days. Finally, the tubes were slowly cooled down to room temperature at a rate of $-2{ }^{\circ} \mathrm{C} / \mathrm{h}$. The ultrasound and anneal temperature depend on the melting point and other properties of the materials. The samples obtained after synthetic procedure were quickly stored in the glove box away from light.

Before measurement, the quartz tubes were carefully opened in the glove box. The evenly black doped samples were taken out and placed in the corresponding glass carrier, sealing membrane, capillary or capsule. The samples must be sealed during measurement because they may contain unreacted alkali metal which is prone to spontaneous combustion once exposed to air.

The crystal structures of samples were characterized with XRD on a Bruker D8 A25 X-ray diffractometer (Bruker, Billerica, MA, USA) (with Cu Ka radiation $(\lambda=1.54 \AA$ ). Magnetization measurements were characterized in a SQUID magnetometer from Quantum Design. The Raman spectra were performed on an in-house system with LabRAM HR Evolution from HORIBA Scientific (Horiba, Kyoto, Japan) of less than $1 \mathrm{~mW}$ power in $633 \mathrm{~nm}$ wavelength.

The plane-wave pseudopotential method as performed in the Vienna ab initio simulation package [32] was employed for the crystal information and electronic structures of potassium doped 2,3-DMN. The electron interaction was modeled by the generalized gradient approximation with Perdew-Burke-Ernzerhof formula [33]. $6 \times 5 \times 3$ MonkhorstPack k-points mesh were used for optimizing geometry structure. A $17 \times 14 \times 10$ k-point sampling scheme was adopted for calculating partial density of states. The convergence criterion for the max force is $0.02 \mathrm{eV} / \AA$, and that of energy is $10^{-5} \mathrm{eV}$.

\section{Results and Discussions}

\subsection{Crystal Structures of Potassium Doped 2,3-DMN}

The molecular structure of 2,3-DMN is shown in Figure 1a, in which white and gray spheres represent hydrogen and carbon atoms respectively. Figure $1 \mathrm{~b}$ shows the appearance of the potassium doped 2,3-DMN samples during preparation. It can be seen that the organic powder which was originally white became grey and condensed at the bottom of the quartz tube after $90^{\circ} \mathrm{C}$ and $10 \mathrm{~h}$ of ultrasonic treatment. Following the annealing process, the sample becomes dark black. The ratio of potassium to 2,3-DMN was set as described in previous report [25]. When the sample was removed from the quartz tube 
for measurement, it was found that there were still lumpy potassium residues in the tube, possibly because the potassium blocks were too large to react completely with the organic material. These potassium blocks were discarded to avoid measurement influence.

(a)
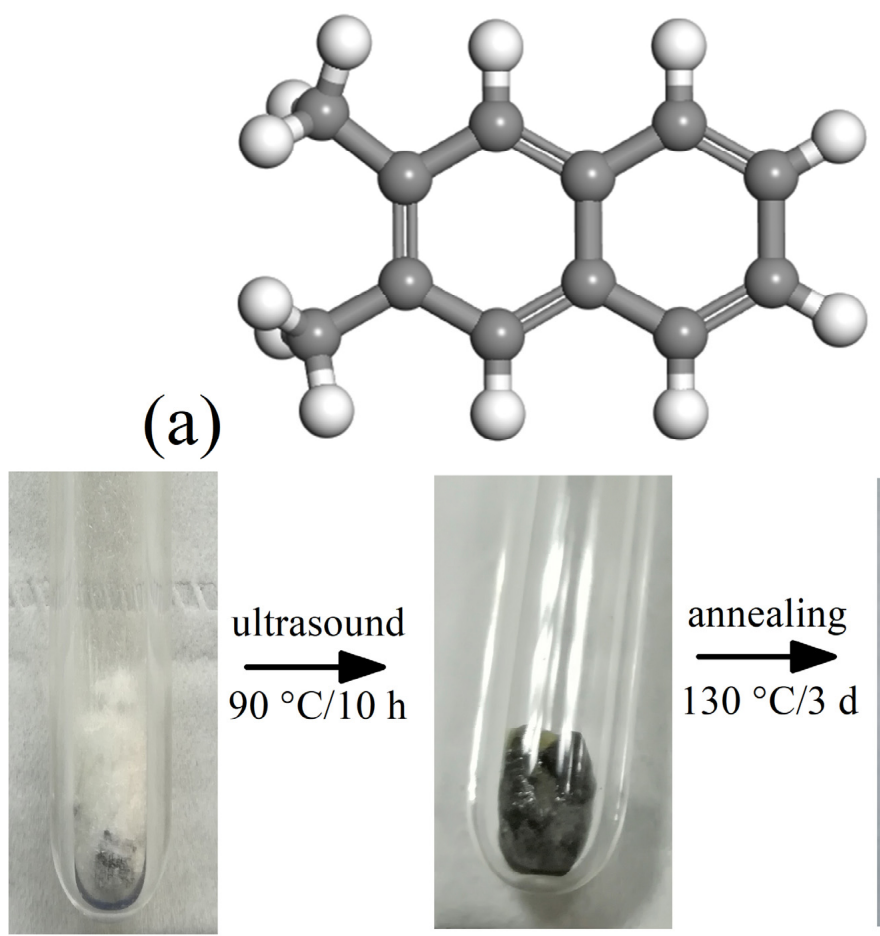

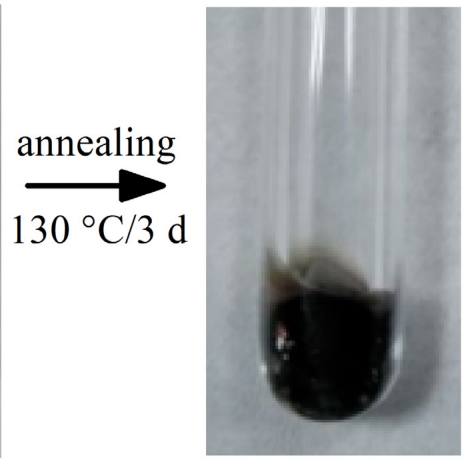

(b)

Figure 1. (a) Molecular structure of 2,3-DMN. (b) Appearance of the potassium doped 2,3-DMN samples during preparation.

Stable insertion crystal structure is the cornerstone for analyzing the properties of doped PAHs. The failure of synthetic products is usually manifested in either no diffraction peak, or only the original peak of pristine organics, or even only the peak of $\mathrm{K}$ or $\mathrm{KH}$ impurities [34]. Figure 2 exhibited XRD of pristine and potassium-doped 2,3-DMN $\left(\mathrm{K}_{\mathrm{x}} 2,3-\right.$ DMN, $x=1$ or 2). Pristine 2,3-DMN samples exhibit obvious peaks at $9.1^{\circ}$ and $18.3^{\circ}$, which represent the planes of (001) and (002), respectively. It can be obviously found that the pristine material has a [001] preferred orientation growth, which was often observed in many purchased pristine PAHs [20]. After doping process, good crystallinity was observed in both two doped samples. The original (001) peak has a $0.2^{\circ}$ shift and some new peaks like $23.7^{\circ}$ appear, which suggests that potassium was inserted into the crystal of 2,3-DMN to form a new stable crystal structure.

In the $\mathrm{K}_{2} 2,3-\mathrm{DMN}$ sample, peaks of $9.3^{\circ}$ and $9.1^{\circ}$ were observed simultaneously, as showed in illustration of Figure 2, indicating the presence of unreacted pristine organics in the sample, which demonstrates that the new peak of $9.3^{\circ}$ could not be caused by the deviation of the instrument. The peaks of the $\mathrm{K}_{1} 2,3-\mathrm{DMN}$ and $\mathrm{K}_{2} 2,3-\mathrm{DMN}$ samples were basically consistent, and no obvious $\mathrm{K}$ or $\mathrm{KH}$ impurity peak appeared, indicating that no significant amount of impurities KH existed in the samples after preparation. It is shown that the potassium doped 2,3-DMN samples with good crystallinity can be synthesized by our process.

Pristine 2,3-DMN has the P21/a space group and its lattice constant [35] are $a=7.916 \AA$, $b=6.052 \AA, c=10.017 \AA, \alpha=90^{\circ}, \beta=105.43^{\circ}, \gamma=90^{\circ}$, and the cell volume is $462.6 \AA^{3}$. The potassium atoms were inserted into the structure of 2,3-DMN according to different stoichiometric ratios, and the atomic position was sufficiently relaxed. Finally, we found that an optimized crystal having a stoichiometric ratio of 1:2 is consistent with the experi- 
mental data. The corresponding XRD spectrum was marked as "Calculated" in Figure 2. The recrystallized samples may have lower crystallinity than the pristine sample. This is a common feature of most of doped PAHs materials [16,25,28]. Our analysis is mainly based on the position and relative strength of the major peaks. As can be seen from Figure 2, most of peaks in the experimental data can be found in the calculation results, and the relative strength is basically the same. The calculation peaks that do not appear in the experimental data may be caused by the preferred orientation of the synthetic sample, which is similar to other reported results of doped PAHs. In fact, the parameter space of stoichiometry and placement of the alkali atoms is huge, and any small change may lead to great fluctuations in the XRD data. For example, XRD data of a theoretical structure with a stoichiometric ratio of 1:1 is shown in Figure A1 of Appendix B. It can be seen that this result is very different from the measured pattern.

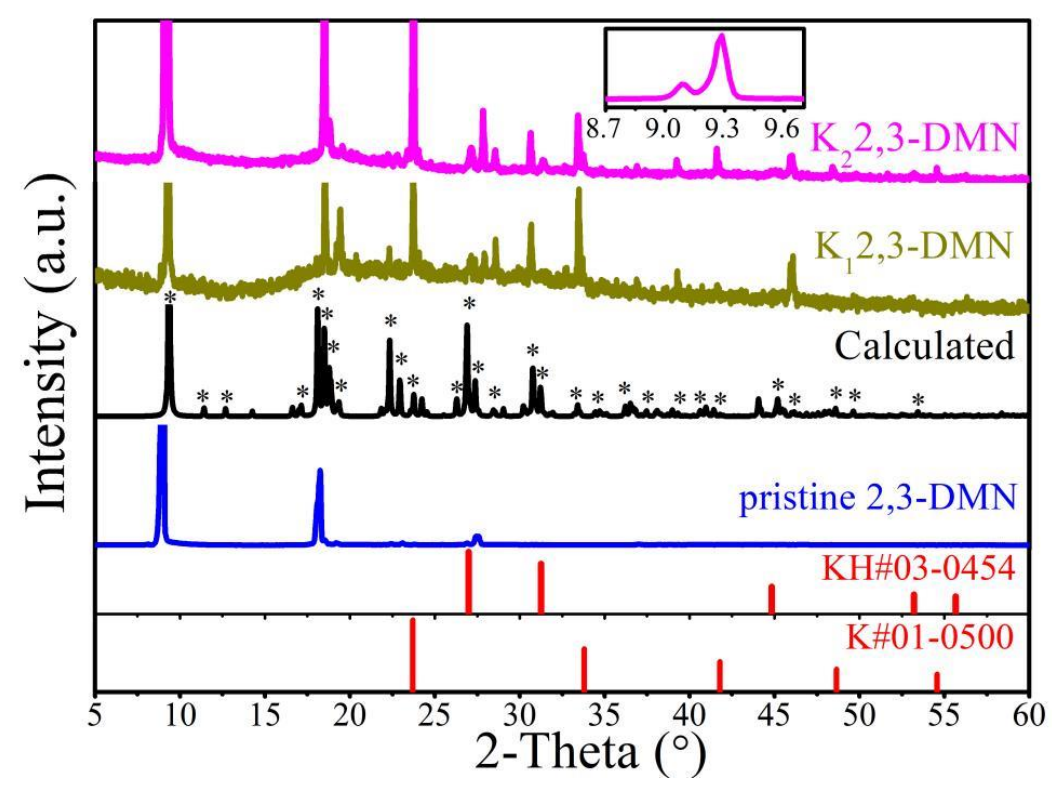

Figure 2. XRD of pristine and potassium-doped 2,3-DMN. "Calculated" represents the calculated XRD of theoretical structure in Section 3.4. " "* represents the calculated peak position consistent with the peak of the experimental curve. The illustration showed the $\mathrm{K}_{2} 2,3-\mathrm{DMN}$ sample data information between $8.7^{\circ}$ and $9.7^{\circ}$.

\subsection{Raman Spectra of Pristine and Potassium-Doped 2,3-DMN}

Raman spectra of pristine and potassium-doped 2,3-DMN were collected to further analyze the changes of electronic structure before and after doping. For Raman measurements of doped samples placed in a capillary tube, we selected uniform black region rather than the white region corresponding to the unreacted organic material. Different regions can be identified from the enlarged image on the light microscope attached to the Raman instrument. The Raman modes of pristine 2,3-DMN include the lattice region, C-C-C bending region, $\mathrm{C}-\mathrm{H}$ bending region, and $\mathrm{C}-\mathrm{C}$ stretching region [36]. The mode at $101 \mathrm{~cm}^{-1}$ is associated with the skeletal deformation of naphthalene. The two modes at 417 and $451 \mathrm{~cm}^{-1}$ correspond to the C-C-C out-plane bending. The corresponding C-H out-plane bending for methyl groups are observed at 740 and $817 \mathrm{~cm}^{-1}$. The mode at $1020 \mathrm{~cm}^{-1}$ belong to the in-plane bending. The frequencies observed at 1386, 1471, and $1577 \mathrm{~cm}^{-1}$ belong to $\mathrm{C}=\mathrm{C}$ stretching [36].

As can be seen from the Figure 3, when potassium is inserted into 2,3-DNM, some modes like 1020 and $1471 \mathrm{~cm}^{-1}$ stay the same, some like 110 and $740 \mathrm{~cm}^{-1}$ disappear, and some new modes appear, such as 612,1310 , and $1520 \mathrm{~cm}^{-1}$. It is worth noting that all of the vibrational modes of the two doped samples are basically the same, indicating that the doping structure is relatively stable. In addition, the rest of modes in the pristine sample 
shift down by $7,15,7,24$, and $20 \mathrm{~cm}^{-1}$ in sequence. The red shift phenomenon observed in the Raman spectra is similar to the result of potassium doped 2,2'-Bipyridine [17], triphenylbismuth [18], and picene [37], due to the softening effect of Raman model. This charge transfer indicates that metal atoms are inserted into organic molecular structures. The width of spectral modes increased obviously in the doped samples, which was caused by electron-phonon interactions. Similar behavior was observed in potassium-doped fullerenes [38].

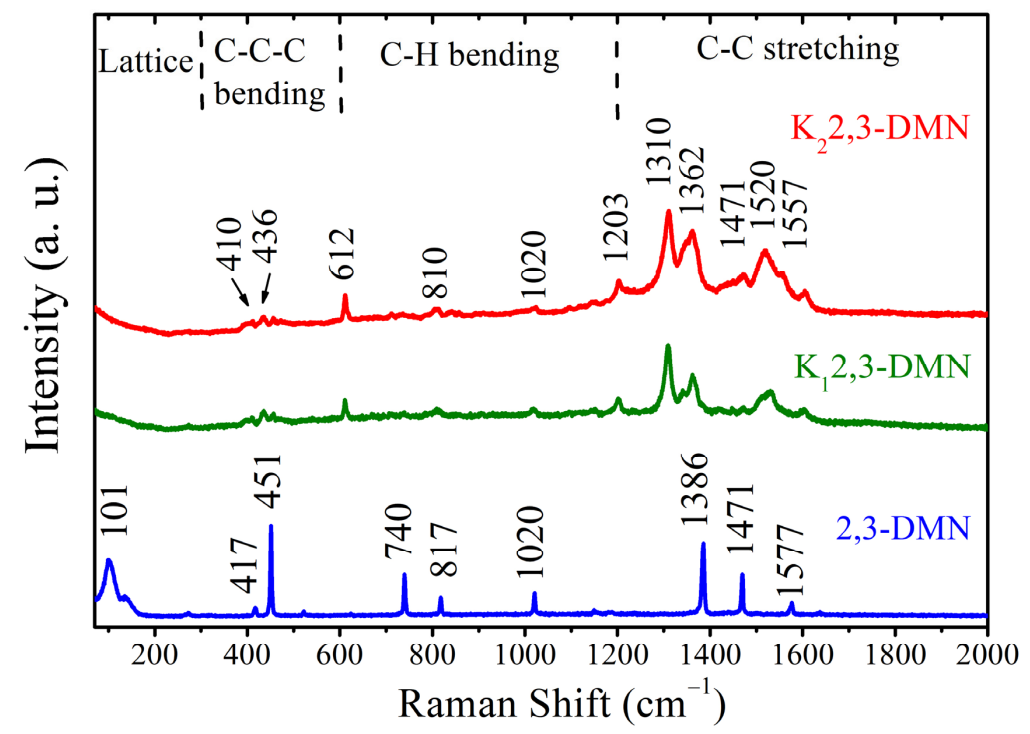

Figure 3. Raman scattering spectra of pristine and potassium-doped 2,3-DMN.

\subsection{Magnetic Property of Potassium-Doped 2,3-DMN}

XRD and Raman measurement indicated that the structures of $\mathrm{K}_{1} 2,3-\mathrm{DMN}$ sample and $\mathrm{K}_{2} 2,3-\mathrm{DMN}$ sample were consistent, so only $\mathrm{K}_{1} 2,3-\mathrm{DMN}$ sample was examined for magnetism. Figure 4 shows the magnetic measurement results of pristine and $\mathrm{K}_{1} 2,3$-DMN sample. The temperature dependence of the magnetic susceptibility $\chi$ was exhibited in Figure 4a. It is seen that pristine 2,3-DMN has weak diamagnetism and negative susceptibility over the entire temperature range.

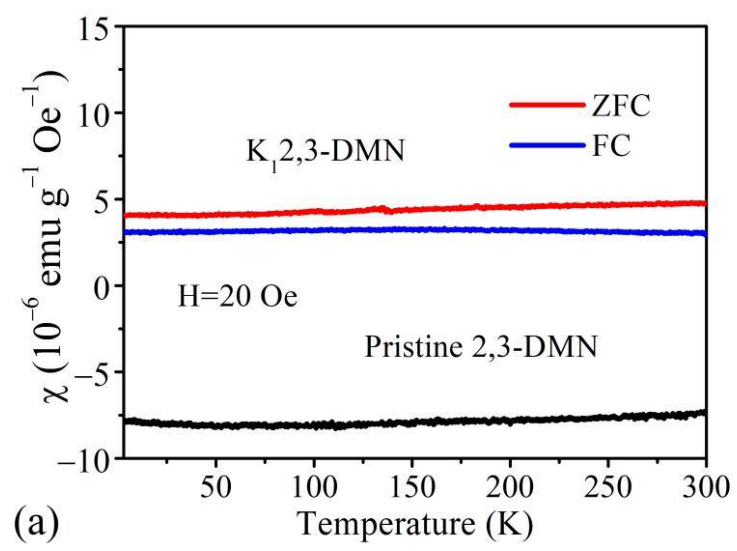

Figure 4. (a) The temperature dependence of the magnetic susceptibility $\chi$ for pristine and potassium-doped 2,3-DMN sample in the temperature range of $1.8 \mathrm{~K}$ to $300 \mathrm{~K}$. (b) The magnetization loops for potassium-doped 2,3-DMN sample at temperature of $1.8 \mathrm{~K}$.

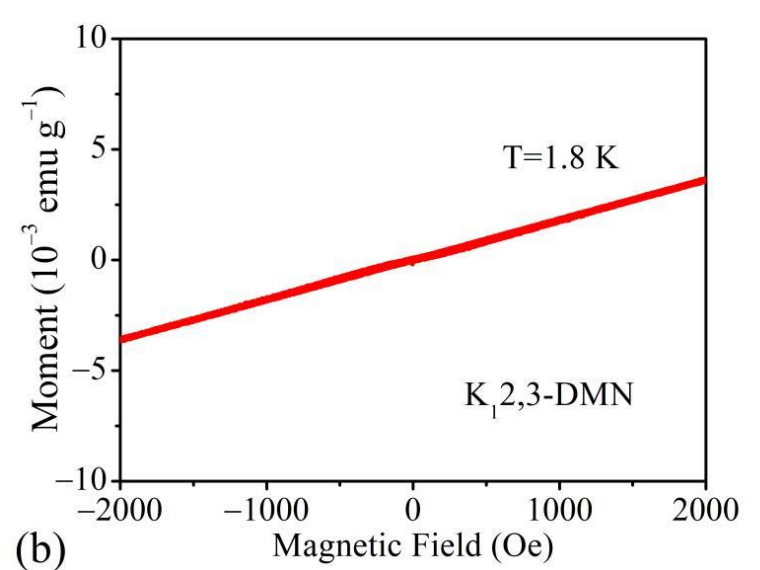

(b)

As shown in Figure 4a, the magnetic susceptibility of $\mathrm{K}_{1} 2,3$-DMN sample became positive and did not change with temperature basically in both ZFC and FC condition after 
doping. Very low magnetic susceptibility of $10^{-6} \mathrm{emu} \cdot \mathrm{g}^{-1} \cdot \mathrm{Oe}^{-1}$ indicates that $\mathrm{K}_{1} 2,3-\mathrm{DMN}$ sample has a weak temperature-dependent Pauli-like behavior, which is similar to the partially low-proportion doped samples of potassium-doped picene [8]. This kind of phenomenon cannot be attributed to potassium metal which has a paramagnetic susceptibility of $4.6 \times 10^{-7} \mathrm{emu} \cdot \mathrm{g}^{-1} \cdot \mathrm{Oe}^{-1}$. The $\chi$-T curve does not conform to the Curie-Weiss Law, revealing that there is no magnetic moment in the samples. Further evidence for the exclusion of magnetic impurities is shown on the magnetization loops for $\mathrm{K}_{1} 2$,3-DMN sample at $1.8 \mathrm{~K}$ in Figure $4 \mathrm{~b}$. As shown in Figure $4 \mathrm{~b}$, with the increase of external magnetic field, the magnetization intensity of the sample increased almost linearly. No obvious hysteresis or bending is observed, indicating that there are no ferromagnetic impurities in the $\mathrm{K}_{1} 2,3-\mathrm{DMN}$ sample. ESR measurements for potassium doped and pristine samples were also performed, and no magnetic impurities were detected in the pristine sample. The signal of doped material exhibits a behavior similar to potassium doped fullerene conductive polymer composites in the Pauli-like range [39]. Therefore, this Pauli-like weak magnetization reflects the nature of potassium doped 2,3-DMN materials.

\subsection{Theoretical Calculation of Potassium Doped 2,3-DMN}

The searched crystal structure is shown in Figure 5a. The theoretical structure belongs to the P1 space group, and two 2,3-DMN molecules and one potassium atom occupy in a unit cell. The lattice parameters are that $a=8.042 \AA, b=6.211 \AA, c=9.799 \AA, \alpha=89.212^{\circ}$, $\beta=105.515^{\circ}, \gamma=91.395^{\circ}$, and the cell volume is $471.5 \AA^{3}$. The positions of each $\mathrm{K}, \mathrm{H}$, and $\mathrm{C}$ atom are listed in Appendix C. The nominal ratios of potassium and 2,3-DMN are 1:1 and $2: 1$, while the theoretically calculated structure has a ratio of $1: 2$. This indicates that only partial potassium does react with 2,3-DMN. According to previous studies, the stoichiometric ratio of the stable structural phase formed after doping is not necessarily equal to the nominal doping ratio, like potassium doped triphenylbismuth [18] and potassium doped pentacene [25]. Generally speaking, in order to ensure the full reaction between alkali metals and organic material, researchers may select appropriate stoichiometric ratio to conduct synthesis in the experimental process. It is an important research topic in this field to determine the doped crystal structure by improving the crystal quality of doped samples.
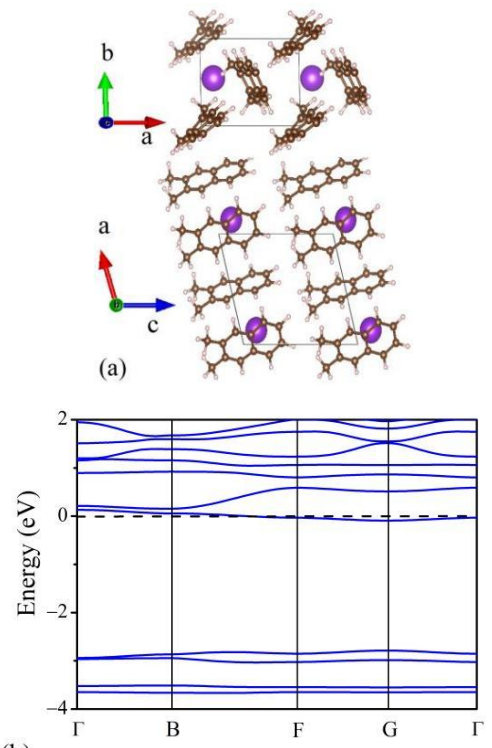

(b)

Figur

Figure 5. (a) The theoretical potassium-doped 2,3-DMN crystal structure in a $2 \times 1 \times 1$ supercell. The brown and purple balls represent $C$ and $K$ atoms, respectively. (b) The band structure of theoretical potassium-doped 2,3-DMN. (c,d) Partial density of states (PDOS) of theoretical potassium-doped 2,3-DMN. (c) PDOS of C 2s (black lines) and C 2p (red lines) orbitals, (d) PDOS of K 3p (red lines) and $\mathrm{K} 4 \mathrm{~s}$ (black lines) orbitals, respectively. 
Compared with the pristine structure, the lattice constants $a$ and $b$ of the theoretical structure expand, whereas the $c$ shrinks with intercalating potassium, suggesting the intercalation of potassium atoms into the $a-b$ plane. The shrink of the $c$ is caused by the strong interaction between the layers of benzene ring due to potassium doping. We also prepared potassium doped 2,3-DMN samples with a stoichiometric ratio of 1:2, and their $\mathrm{XRD}$, Raman, and magnetic measurement were not significantly different from $\mathrm{K}_{1} 2,3$-DMN and $\mathrm{K}_{2} 2,3-\mathrm{DMN}$ samples.

Based on the theoretical potassium-doped 2,3-DMN structure, the energies in the three configurations of non-magnetic, antiferromagnetic, and ferromagnetic were calculated, as listed in Appendix A. The obtained results showed that the energy of non-magnetic configuration is much lower than these of the other two configurations, indicating that the doping does not form local magnetic moment in organic structures. This result is consistent with the experiment.

The band structure of theoretical potassium-doped 2,3-DMN is presented in Figure 5b, and the partial density of states (PDOS) of $C$ and $K$ are presented in Figure $5 c, d$, respectively. The Fermi level marked by black lines crossing two bands shown in Figure $5 \mathrm{~b}$ suggests the doped structure becomes metallic. The PDOS shown in Figure $5 c$,d indicate that the C $2 p$ orbitals contribute the most to the state around the Fermi level, while the K $4 \mathrm{~s}$ and $\mathrm{C} 2 \mathrm{~s}$ orbitals contribute very little. Therefore, this confirms the transfer of electrons from $\mathrm{K} 4 \mathrm{~s}$ to the C $2 p$ orbital.

Temperature-independent Pauli susceptibility has been found in multi-shell nanographite which is responsible by the propagation of conductive $\pi$-carriers [7]. Theoretical calculations show that potassium-doped 2,3-DMN with similar $\pi$-electron structure also exhibits a metallic state, which should be the cause of temperature-independent magnetic behavior. According to previous reports, doping concentration and crystal structure play an important role in the physical properties of alkaline metal-doped PAHs, such as rubidium-doped phenanthrene [9] and potassium-doped pentacene [25]. If the doping concentration could be changed or the intermolecular distance is modulated by compression, localized magnetic moment may be formed on the 2,3-DMN molecule structure, leading to novel magnetism.

\section{Conclusions}

Potassium-doped 2,3-dimethylnaphthalene molecular crystals are successfully synthesized. XRD and Raman measurements confirm that potassium atoms are inserted into organic molecules to form new stable structures. The magnetic measurements indicate that the synthesized materials have a temperature-independent paramagnetic behavior in the whole temperature range. First-principles calculation reveals that the doped crystal structure changes from P21/a to the P1 space group, as well as the expansion of the lattice parameters. The calculated electronic structure shows that the $\mathrm{K}$ 4s electrons transfer to the C 2p orbital, and the sample has a metallic state. This study is of great significance for the synthesis of alkali metal doped organic molecular crystals and the understanding of their physical properties.

Author Contributions: Conceptualization, X.-L.W. and Z.-B.H.; data curation, Z.-B.H.; formal analysis, Y.G.; investigation, X.-J.C.; methodology, R.-S.W. and M.-A.F.; resources, S.-C.F.; software, H.Y. and J.Z.; validation, S.-C.F.; writing-original draft, X.-L.W.; review and editing all authors. All authors have read and agreed to the published version of the manuscript.

Funding: This work was supported by the National Natural Science Foundation of China under Grants Nos. 11904090, 91221103, and 11574076. The work at HPSTAR was supported by the National Key R\&D Program of China (Grant No. 2018YFA0305900).

Data Availability Statement: Data are contained within the article. 
Acknowledgments: This work was supported by the National Natural Science Foundation of China under Grants Nos. 11904090, 91221103, and 11574076. The work at HPSTAR was supported by the National Key R\&D Program of China (Grant No. 2018YFA0305900). The financial support is greatfully acknowledged.

Conflicts of Interest: The authors declare no conflict of interest.

\section{Appendix A}

Table A1. The energy in the three configurations of potassium doped 2,3-dimethylnaphthalene theoretical structure.

\begin{tabular}{cc}
\hline Configuration & Energy \\
\hline intralayer AFM, interlayer FM & -612.84848322 \\
intralayer FM, interlayer AFM & -612.84859219 \\
FM & -612.85092251 \\
NM & -613.07384680 \\
\hline
\end{tabular}

\section{Appendix B}

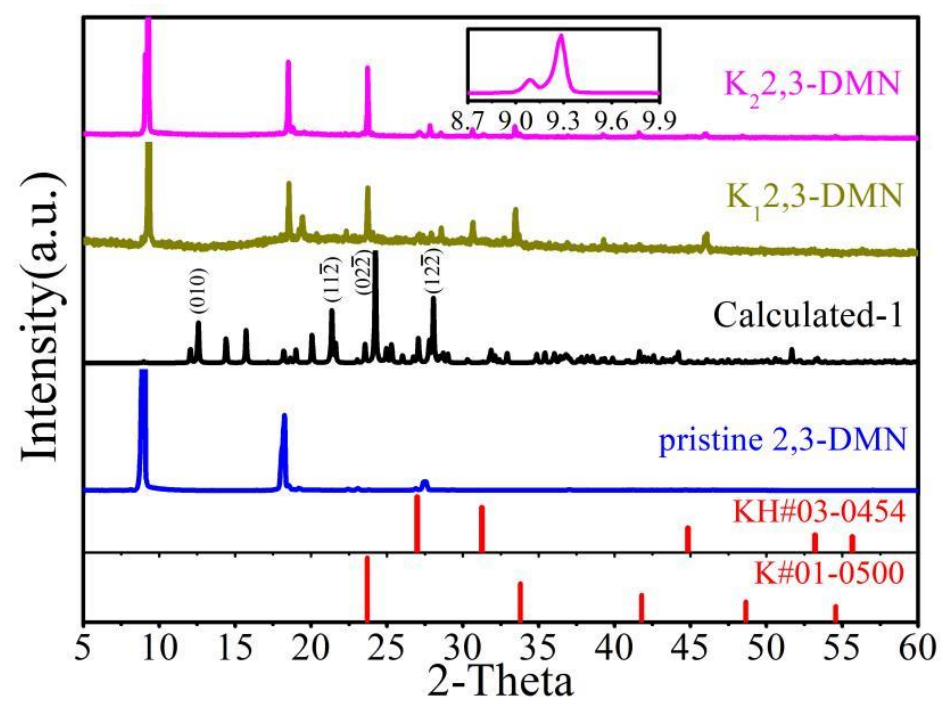

Figure A1. XRD of experimental samples and a theoretically predicted structure with stoichiometric ratio of 1:1. "Calculated-1" represents XRD data of the theoretical structure.

\section{Appendix C}

data_VESTA_phase_1

_chemical_name_common '41006'

_cell_length_a 8.042

_cell_length_b 6.21106

_cell_length_c $\quad 9.79917$

_cell_angle_alpha $\quad 89.21175$

_cell_angle_beta 105.5153

_cell_angle_gamma $\quad 91.3946$

_space_group_name_H-M_alt P P 1

_space_group_IT_number 1

loop_

_space_group_symop_operation_xyz

'x, $\quad \mathrm{y}, \quad$ z'




\begin{tabular}{|c|c|c|c|c|c|c|c|}
\hline \\
\hline \multicolumn{8}{|c|}{$\begin{array}{l}\text { loop_ } \\
\text { atom site label }\end{array}$} \\
\hline \multicolumn{8}{|c|}{ _atom_site_occupancy } \\
\hline \multicolumn{8}{|c|}{ _atom_site_fract_x } \\
\hline \multicolumn{8}{|c|}{ _atom_site_fract_y } \\
\hline \\
\hline \multicolumn{8}{|c|}{ _atom_site_adp_type } \\
\hline \multicolumn{8}{|c|}{ _atom_site_B_iso_or_equiv } \\
\hline \multicolumn{8}{|c|}{ _atom_site_type_symbol } \\
\hline $\mathrm{C} 1$ & 1.0 & 0.114196 & 0.151056 & 0.955084 & Biso & 1.000000 & $\mathrm{C}$ \\
\hline $\mathrm{C} 2$ & 1.0 & 0.088656 & 0.067549 & 0.083604 & Biso & 1.000000 & $\mathrm{C}$ \\
\hline $\mathrm{C} 3$ & 1.0 & 0.200723 & 0.112914 & 0.220531 & Biso & 1.000000 & $\mathrm{C}$ \\
\hline $\mathrm{C} 4$ & 1.0 & 0.162878 & 0.035729 & 0.344154 & Biso & 1.000000 & $\mathrm{C}$ \\
\hline $\mathrm{C} 5$ & 1.0 & 0.014221 & 0.909059 & 0.335237 & Biso & 1.000000 & $\mathrm{C}$ \\
\hline $\mathrm{C} 6$ & 1.0 & 0.905212 & 0.853901 & 0.202767 & Biso & 1.000000 & $\mathrm{C}$ \\
\hline $\mathrm{C} 7$ & 1.0 & 0.406677 & 0.701949 & 0.940478 & Biso & 1.000000 & $\mathrm{C}$ \\
\hline $\mathrm{C} 8$ & 1.0 & 0.407115 & 0.600886 & 0.814374 & Biso & 1.000000 & $\mathrm{C}$ \\
\hline C9 & 1.0 & 0.494479 & 0.403442 & 0.820114 & Biso & 1.000000 & $\mathrm{C}$ \\
\hline $\mathrm{C} 10$ & 1.0 & 0.486328 & 0.611038 & 0.074947 & Biso & 1.000000 & $\mathrm{C}$ \\
\hline $\mathrm{C} 11$ & 1.0 & 0.319007 & 0.705281 & 0.675387 & Biso & 1.000000 & $\mathrm{C}$ \\
\hline $\mathrm{C} 12$ & 1.0 & 0.505051 & 0.290604 & 0.68797 & Biso & 1.000000 & $\mathrm{C}$ \\
\hline $\mathrm{C} 13$ & 1.0 & 0.849642 & 0.848233 & 0.939907 & Biso & 1.000000 & $\mathrm{C}$ \\
\hline $\mathrm{C} 14$ & 1.0 & 0.88373 & 0.92397 & 0.814587 & Biso & 1.000000 & $\mathrm{C}$ \\
\hline $\mathrm{C} 15$ & 1.0 & 0.009763 & 0.088633 & 0.821767 & Biso & 1.000000 & $\mathrm{C}$ \\
\hline $\mathrm{C} 16$ & 1.0 & 0.94171 & 0.925793 & 0.075084 & Biso & 1.000000 & $\mathrm{C}$ \\
\hline $\mathrm{C} 17$ & 1.0 & 0.790756 & 0.824074 & 0.675707 & Biso & 1.000000 & $\mathrm{C}$ \\
\hline $\mathrm{C} 18$ & 1.0 & 0.033521 & 0.19521 & 0.689696 & Biso & 1.000000 & $\mathrm{C}$ \\
\hline C19 & 1.0 & 0.571196 & 0.30993 & 0.951347 & Biso & 1.000000 & $\mathrm{C}$ \\
\hline $\mathrm{C} 20$ & 1.0 & 0.568179 & 0.406515 & 0.080511 & Biso & 1.000000 & $\mathrm{C}$ \\
\hline $\mathrm{C} 21$ & 1.0 & 0.644021 & 0.31107 & 0.215124 & Biso & 1.000000 & $\mathrm{C}$ \\
\hline $\mathrm{C} 22$ & 1.0 & 0.638142 & 0.412428 & 0.339016 & Biso & 1.000000 & $\mathrm{C}$ \\
\hline $\mathrm{C} 23$ & 1.0 & 0.559893 & 0.613891 & 0.333997 & Biso & 1.000000 & $\mathrm{C}$ \\
\hline $\mathrm{C} 24$ & 1.0 & 0.488316 & 0.713596 & 0.204325 & Biso & 1.000000 & $\mathrm{C}$ \\
\hline $\mathrm{H} 1$ & 1.0 & 0.223673 & 0.261205 & 0.958412 & Biso & 1.000000 & $\mathrm{H}$ \\
\hline $\mathrm{H} 2$ & 1.0 & 0.322198 & 0.201667 & 0.228884 & Biso & 1.000000 & $\mathrm{H}$ \\
\hline H3 & 1.0 & 0.250535 & 0.074133 & 0.447204 & Biso & 1.000000 & $\mathrm{H}$ \\
\hline $\mathrm{H} 4$ & 1.0 & -0.017223 & 0.85067 & 0.431069 & Biso & 1.000000 & $\mathrm{H}$ \\
\hline H5 & 1.0 & 0.79334 & 0.748512 & 0.19647 & Biso & 1.000000 & $\mathrm{H}$ \\
\hline H6 & 1.0 & 0.343391 & 0.856707 & 0.936103 & Biso & 1.000000 & $\mathrm{H}$ \\
\hline H7 & 1.0 & 0.225582 & 0.595793 & 0.605182 & Biso & 1.000000 & $\mathrm{H}$ \\
\hline $\mathrm{H} 8$ & 1.0 & 0.474723 & 0.395308 & 0.593875 & Biso & 1.000000 & $\mathrm{H}$ \\
\hline H9 & 1.0 & 0.747785 & 0.726156 & 0.93348 & Biso & 1.000000 & $\mathrm{H}$ \\
\hline H10 & 1.0 & 0.704658 & 0.692244 & 0.692182 & Biso & 1.000000 & $\mathrm{H}$ \\
\hline H11 & 1.0 & 0.920881 & 0.292603 & 0.637318 & Biso & 1.000000 & $\mathrm{H}$ \\
\hline H12 & 1.0 & 0.636715 & 0.157033 & 0.955037 & Biso & 1.000000 & $\mathrm{H}$ \\
\hline $\mathrm{H} 13$ & 1.0 & 0.70774 & 0.157 & 0.219115 & Biso & 1.000000 & $\mathrm{H}$ \\
\hline H14 & 1.0 & 0.695668 & 0.33595 & 0.441159 & Biso & 1.000000 & $\mathrm{H}$ \\
\hline H15 & 1.0 & 0.559654 & 0.6954 & 0.431776 & Biso & 1.000000 & $\mathrm{H}$ \\
\hline H16 & 1.0 & 0.432267 & 0.872538 & 0.200467 & Biso & 1.000000 & $\mathrm{H}$ \\
\hline H17 & 1.0 & 0.411482 & 0.758277 & 0.615964 & Biso & 1.000000 & $\mathrm{H}$ \\
\hline H18 & 1.0 & 0.24926 & 0.847339 & 0.693349 & Biso & 1.000000 & $\mathrm{H}$ \\
\hline H19 & 1.0 & 0.414581 & 0.151399 & 0.665431 & Biso & 1.000000 & $\mathrm{H}$ \\
\hline $\mathrm{H} 20$ & 1.0 & 0.63504 & 0.226898 & 0.701993 & Biso & 1.000000 & $\mathrm{H}$ \\
\hline $\mathrm{H} 21$ & 1.0 & 0.047344 & 0.079713 & 0.609602 & Biso & 1.000000 & $\mathrm{H}$ \\
\hline $\mathrm{H} 22$ & 1.0 & 0.147166 & 0.30322 & 0.71364 & Biso & 1.000000 & $\mathrm{H}$ \\
\hline $\mathrm{H} 23$ & 1.0 & 0.881972 & 0.755462 & 0.622526 & Biso & 1.000000 & $\mathrm{H}$ \\
\hline $\mathrm{H} 24$ & 1.0 & 0.71348 & 0.940499 & 0.600251 & Biso & 1.000000 & $\mathrm{H}$ \\
\hline K1 & 1.0 & 0.129492 & 0.546597 & 0.139255 & Biso & 1.000000 & K \\
\hline
\end{tabular}




\section{References}

1. Hannay, N.B.; Geballe, T.H.; Matthias, B.T.; Abndres, K.; Schmidt, F.; MacNair, D. Superconductivity in graphitic compounds. Phys. Rev. Lett. 1965, 14, 225-226. [CrossRef]

2. Emery, N.; Hérold, C.; D'Astuto, M.; Garcia, V.; Bellin, C.; Mareche, J.F.; Lagrange, P.; Loupias, G. Superconductivity of bulk CaC 6 . Phys. Rev. Lett. 2005, 95, 087003.1-087003.4. [CrossRef] [PubMed]

3. Hebard, A.F.; Rosseinsky, M.J.; Haddon, R.C.; Murphy, D.W.; Glarum, S.H.; Palstra, T.T.M.; Ramirez, A.P.; Kortan, A.R. Superconductivity at $18 \mathrm{~K}$ in potassium-doped $\mathrm{C}_{60}$. Nature 1991, 350, 600-601. [CrossRef]

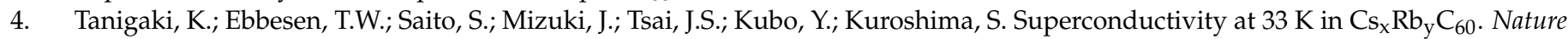
1991, 352, 222-223. [CrossRef]

5. Takabayashi, Y.; Ganin, A.Y.; Jeglic, P.; Arcon, D.; Takano, T.; Iwasa, Y.; Ohishi, Y.; Takata, M.; Takeshita, M.; Prassides, K.; et al. The Disorder-Free Non-BCS Superconductor $\mathrm{Cs}_{3} \mathrm{C}_{60}$ Emerges from an Antiferromagnetic Insulator Parent State. Science 2009, 323, 1585-1590. [CrossRef]

6. Ganin, A.Y.; Takabayashi, Y.; Khinyak, Y.Z.; Margadonna, S.; Tamai, A.; Rosseinsky, M.J.; Prassides, K. Bulk superconductivity at $38 \mathrm{~K}$ in a molecular system. Nat. Mater. 2008, 7, 367-371. [CrossRef] [PubMed]

7. Osipov, V.Y.; Shames, A.I.; Enoki, T.; Takai, K.; Endo, M.; Hayashi, T.; Kaburagi, Y.; Vul, A.Y. Magnetic and EPR studies of edge-localized spin paramagnetism in multi-shell nanographites derived from nanodiamonds. Diam. Relat. Mater. 2009, 18, 220-223. [CrossRef]

8. Mitsuhashi, R.; Suzuki, Y.; Yamanari, Y.; Mitamura, H.; Kambe, T.; Ikeda, R.; Okamoto, H.; Fujiwara, A.; Yamaji, M.; Kawasaki, N. Superconductivity in alkali-metal-doped picene. Nature 2010, 464, 76-79. [CrossRef]

9. Wang, X.F.; Liu, R.H.; Gui, Z.; Xie, Y.L.; Yan, Y.J.; Ying, J.J.; Luo, X.G.; Chen, X.H. Superconductivity at 5 K in Alkali-Metal-Doped Phenanthrene. Nat. Commun. 2012, 2, 507. [CrossRef]

10. Malavasi, L.; Hammerath, F.; Margadonna, S.; Artioli, G.A.; Corana, F. Superconductivity in sm-doped [n]phenacenes $(\mathrm{n}=3,4,5)$. Chem. Commun. 2014, 51, 1092-1095.

11. Xue, M.; Cao, T.; Wang, D.; Wu, Y.; Yang, H.; Dong, X.; He, J.; Li, F.; Chen, G.F. Superconductivity above 30 K in Alkali-Metal-Doped Hydrocarbon. Sci. Rep. 2012, 2, 389. [CrossRef]

12. Kubozono, Y.; Mitamura, H.; Lee, X.; He, X.; Yamanari, Y.; Takahashi, Y.; Suzuki, Y.; Kaji, Y.; Eguchi, R.; Akaike, K. Metalintercalated aromatic hydrocarbons: A new class of carbon-based superconductors. Phys. Chem. Chem. Phys. 2011, 13, 16476-16493. [CrossRef]

13. Zhong, G.H.; Yang, D.Y.; Zhang, K.; Wang, R.S.; Zhang, C.; Lin, H.Q.; Chen, X.J. Superconductivity and Phase Stability of Potassium-Doped Biphenyl. Phys. Chem. Chem. Phys. 2018, 20, 25217-25223. [CrossRef] [PubMed]

14. Wang, R.S.; Gao, Y.; Huang, Z.B.; Chen, X.J. Superconductivity above 120 kelvin in a chain link molecule. arXiv 2017, arXiv:1703.06641.

15. Yan, J.F.; Zhong, G.H.; Wang, R.S.; Zhang, K.; Lin, H.Q.; Chen, X.J. Superconductivity and Phase Stability of Potassium-Intercalated p-Quaterphenyl. J. Phys. Chem. Lett. 2018, 10, 40-47. [CrossRef] [PubMed]

16. Huang, G.; Zhong, G.H.; Wang, R.S.; Han, J.X.; Lin, H.Q.; Chen, X.J. Superconductivity and phase stability of potassium-doped p-quinquephenyl. Carbon 2019, 143, 837-843. [CrossRef]

17. Peng, D.; Wang, R.S.; Chen, X.J. Superconductivity in Sodium Potassium Alloy Doped 2,2'-Bipyridine from Near Room Temperature Synthesis. J. Phys. Chem. C 2020, 124, 906-912. [CrossRef]

18. Wang, R.S.; Cheng, J.; Wu, X.L.; Yang, H.; Chen, X.J.; Gao, Y.; Huang, Z.B. Superconductivity at 3.5 K and/or 7.2 K in PotassiumDoped Triphenylbismuth. J. Chem. Phys. 2018, 149, 144502. [CrossRef]

19. Wang, R.S.; Yang, H.; Cheng, J.; Wu, X.L.; Fu, M.A.; Chen, X.J.; Gao, Y.; Huang, Z.B. Discovery of Superconductivity in Potassium-Doped Tri-p-Tolylbismuthine. J. Phys. Chem. C 2019, 123, 19105-19111. [CrossRef]

20. Wang, R.S.; Chen, L.C.; Yang, H.; Fu, M.A.; Cheng, J.; Wu, X.L.; Gao, Y.; Huang, Z.B.; Chen, X.J. Superconductivity in an Organometallic Compound. Phys. Chem. Chem. Phys. 2019, 21, 25976-25981. [CrossRef]

21. Fu, M.A.; Wang, R.S.; Yang, H.; Zhang, P.Y.; Zhang, C.F.; Chen, X.J.; Gao, Y.; Huang, Z.B. $\pi$-electron weak ferromagnetism in potassium-intercalated 9-phenylanthracene. Carbon 2021, 173, 587-593. [CrossRef]

22. Takabayashi, Y.; Menelaou, M.; Tamura, H.; Takemori, N.; Prassides, K. $\pi$-Electron $S=1 / 2$ Quantum Spin-Liquid State in an Ionic Polyaromatic Hydrocarbon. Nat. Chem. 2017, 9, 635-643. [CrossRef]

23. Štefančic, A.; Klupp, G.; Knaflic, T.; Yufit, D.S.; Tavčar, G.; Potočnik, A.; Beeby, A.; Arčon, D. Triphenylide-based molecular solid-A new candidate for a quantum spin-liquid compound. J. Phys. Chem. C 2017, 121, 14864-14871. [CrossRef]

24. Phan, Q.T.N.; Heguri, S.; Tanabe, Y.; Shimotani, H.; Nakano, T.; Nozue, Y.; Tanigaki, K. Tuning of the ground state in electron doped anthracene. Dalton Trans. 2014, 43, 10040-10045. [CrossRef]

25. Romero, F.D.; Pitcher, M.J.; Hiley, C.I.; Whitehead, G.F.S.; Kar, S.; Ganin, A.Y.; Antypov, D.; Collins, C.; Dyer, M.S.; Klupp, G. Redox-controlled potassium intercalation into two polyaromatic hydrocarbon solids. Nat. Chem. 2017, 9, 644-652. [CrossRef] [PubMed]

26. Gadjieva, N.A.; Szirmai, P.; Sági, O.; Alemany, P.; Nuckolls, C. Intermolecular resonance correlates electron pairs down a supermolecular chain: Antiferromagnetism in k-doped p-terphenyl. J. Am. Chem. Soc. 2020, 142, 20624-20630. [CrossRef]

27. Guijarro, A.; Verges, J.A. Prediction of a metallic phase for $\mathrm{Cs}_{3}$ pentacene compound. Mater. Res. Express 2018, 5, 066554. [CrossRef] 
28. Yoon, T.; Park, I.; Nguyen, T.P.; Kim, D.Y.; Choi, H.C. Discovery of sodium-doped triphenylene superconductor through searching the organic material database. Chem. Mater. 2020, 32, 3358-3364. [CrossRef]

29. Kowalczuk, M.; Kurcok, P.; Glowkowski, W.; Jedlinski, Z. New reactions of potassium naphthalenide with $\beta-, \gamma-$, and $\delta$-lactones: An efficient route to $\alpha$-alkyl $\gamma$ - and $\delta$-lactones and $\alpha, \beta$-unsaturated carboxylic acid esters. J. Org. Chem. 1992, 57, $389-391$. [CrossRef]

30. Scott, T.A.; Ooro, B.A.; Collins, D.J.; Shatruk, M.; Yakovenko, A.; Dunbar, K.R.; Zhou, H.C. After 118 years, the isolation of two common radical anion reductants as simple, stable solids. Chem. Commun. 2008, 1, 65-67. [CrossRef] [PubMed]

31. Marik, A.; Kumar, C.B.S.; Mohakud, S. Compensated ferrimagnetism and half metallic behavior in potassium(k) intercalated naphthalene. Phys. Status Solidi B 2020, 257, 2000398. [CrossRef]

32. Kresse, G.; Jü, H. ab initio molecular dynamics for liquid metals. Phys. Rev. B 1993, 48, 13115-13118. [CrossRef]

33. Perdew, J.P.; Burke, K.; Ernzerhof, M. Generalized gradient approximation made simple. Phys. Rev. Lett. 1996, 77, 3865-3868. [CrossRef]

34. Heguri, S.; Kobayashi, M.; Tanigaki, K. Questioning the existence of superconducting potassium doped phases for aromatic hydrocarbons. Phys. Rev. B 2015, 92, 014502. [CrossRef]

35. Karl, N.; Heym, H.; Stezowski, J.J. Structure, phase diagram and fluorescence spectra of 2,3-dimethylnaphthalene (anthracene) mixed crystals. Mol. Cryst. Liq. Cryst. 2012, 131, 163-191. [CrossRef]

36. Prabhu, T.; Periandy, S.; Mohan, S. Spectroscopic (FTIR and FT raman) analysis and vibrational study on 2,3-dimethyl naphthalene using ab-initio HF and DFT calculations. Spectroc. Acta Pt. A Molec. Biomolec. Spectr. 2011, 78, 566-574. [CrossRef] [PubMed]

37. Kambe, T.; He, X.; Takahashi, Y.; Yamanari, Y.; Teranishi, K.; Mitamura, H.; Shibasaki, S.; Tomita, K.; Eguchi, R.; Goto, H.; et al. Synthesis and physical properties of metal-doped picene solids. Phys. Rev. B 2012, 86, 214507. [CrossRef]

38. Zhou, P.; Wang, K.A.; Wang, Y.; Eklund, P.C.; Dresselhaus, M.S.; Dresselhaus, G.; Jishi, R.A. Raman scattering in $\mathrm{C}_{60}$ and alkali-metal-saturated $\mathrm{C}_{60}$. Phys. Rev. B 1992, 46, 2595-2605. [CrossRef]

39. Araki, H.; Zakhidov, A.A.; Tada, K.; Yakushi, K.; Yoshino, K. Alkali-metal doping of fullerene-conducting polymer composite: Evolution of conductivity and ESR. Synth. Met. 1996, 77, 291-297. [CrossRef] 